\section{The Precambrian-Cambrian Boundary}

\section{J.W. Cowie and M.D. Brasier (eds.)}

Oxford Science Publications, Clarendon Press, Oxford, UK, 1989, 213 p., hardbound, US $\$ 85.00$ plus $\$ 2.00$ postage and handling. (Order from Oxford University Press, Attention: Order Department, 2001 Evans Rd., Cary, North Carolina 27513, USA)

The problem of the PrecambrianCambrian boundary has been drawing the attention of the scientific community for many years. Since 1972, the Working Group on the Precambrian-Cambrian Boundary has been considering this issue, and during these nearly 20 years, tremendous progress has been made in the study of units that are transitional from the Precambrian to the Cambrian. Interest has not decreased, as this boundary is one of the crucial (key) problems in the development of the organic world (the biosphere as a whole).
In this connection, a generalization of the results on this issue is, at each step, always of much interest. In this book edited by J.W. Cowie and M.D. Brasier, we see the British view on the PrecambrianCambrian boundary. But because the authors of the book are, without any doubt, noted experts on this problem, their views might be considered almost objective.

In the preface of the book is a brief but still exhaustive history of the working group's activity, including references to the achieved intermediate agreements. An exception to this is a decision that is not mentioned here but was accepted at a meeting in Cambridge, UK, in 1978: "The PrecambrianCambrian boundary stratotype point should be placed as close as is practicable to the base of the oldest stratigraphical unit to yield Tommotian (sensu lato) fossil assemblages" (Cowie, J.W., 1978, Geological Magazine, v. 115 , p. 151). This is very important because, in the working group's further activity, a trend arose to place the boundary according to the change in "trace fossils" (Harlaniella podolica for Phycodes pedum) and to set up a standard on Newfoundland, Canada. This, however, means a sharp change from the agreements in Cambridge because this latter boundary is much lower.

In the concise information given in this book on the results of the work in Newfoundland, S. Conway Morris fails to notice this problem at all. Morris believes that the base of Unit 2 of the Chapel Island Formation corresponds in its age to, approximately, the base of the Tommotian Stage.

The chapters following the preface present regional stratigraphic reviews, and material is given here in greater detail on Newfoundland, the UK, and China. A large group of key sections is included in the chapter entitled "China and the Palaeothyan Belt" (India; Pakistan; Iran; Kazakhstan, USSR; and Mongolia). This information is rather full and very useful. However, where Palaeotethys was situated at that time still remains unclear. The description of these sections in one chapter seems to be possible formally, but the idea that the Meishucun section is a key (reference) section for the whole of this territory, which comes from the notion of Palaeotethys, is hardly correct. Brasier's attempt to collate all these sections on the basis of the zonal chart of China (fig. 3.12) substantiates brilliantly all that is said

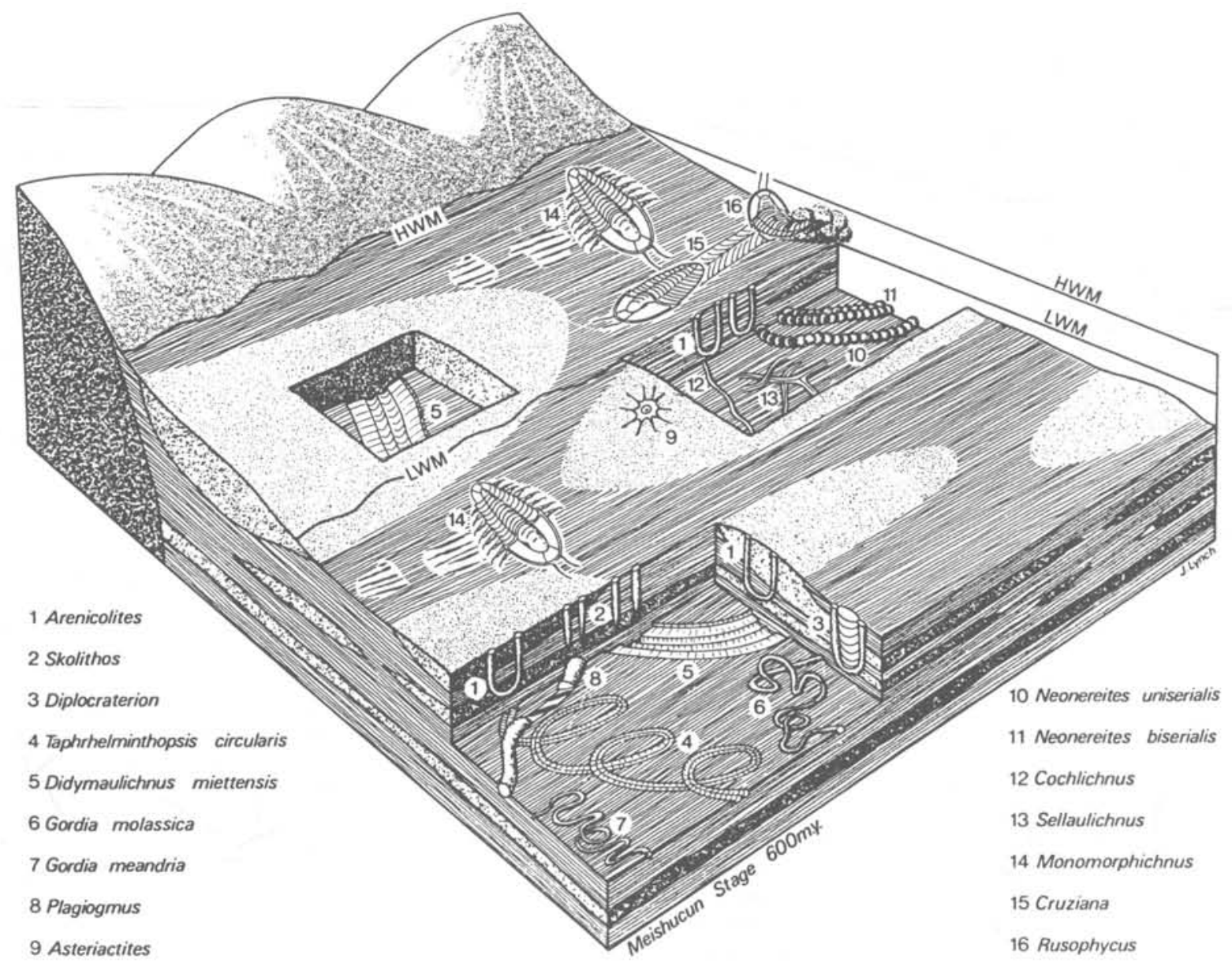


above. Brasier manages to give much more distinct notions of interregional correlation in chapter 7, "Towards a Biostratigraphy of the Earliest Skeletal Biota," where he uses zonal and stage sequences of the Siberian Platform (figs. 7.11, 7.12, 7.13, and 7.14).

Of special interest in chapter 7 is the author's attempt to denote the principal problems in the study of the PrecambrianCambrian boundary and to show the state of the question of the subdivision of Lower Cambrian strata into stages. An important component is the estimation of regularities in the evolution of certain groups of organisms that were represented at that time.

A separate chapter on trace fossils by T.P. Crimes gives a clear notion of the state of knowledge of trace fossils at this boundary interval. It is all the more clear because the author personally has studied many of the key sections.

Chapter 9 on chronometry sums up much of the data that was known at the time this book was written regarding the radiometric ages from the base of the Sinian (sensu stricto)-Vendian to the beginning of the Ordovician. A lot of contradictions in the data interfere with the possibility of making certain conclusions, and they naturally indicate analyses and methods of different quality. An accepted number of $570 \mathrm{Ma}$ reflects but a certain compromise within a range between about $600 \mathrm{Ma}$ and about $530 \mathrm{Ma}$, as is noted justly by the authors (Cowie and W.B. Harland). Divisions before and after the Precambrian-Cambrian boundary are discussed specially in this chapter. As previously (Harland, W.B., and others, 1982, A geologic time scale: Cambridge, UK, Cambridge University Press. 131 p.), names are suggested for the Cambrian series, and a new name--Etchemiznian-is suggested for the Lower Cambrian strata found between the first appearance of Phycodes pedum and the trilobite-bearing rocks in Newfoundland. In table 9.1, however, this new subdivision is placed between the Tommotian Stage of the Cambrian and the Vendian of the Precambrian, which thus does not correspond to the definition in the text.

A special short chapter (chapter 10) entitled "Palaeoclimatology" is devoted instead to a definition of the principal regions for further work on the problem of the late Sinian glacial epoch, as its author, Harland, writes.

The last chapter of the book, chapter 11 , contains closing commentaries and brief accounts of a number of events connected with the transitional interval from the Precambrian to the Cambrian. The chapter also includes information on the results of voting that was carried out concerning Newfoundland during the excursion in 1987. as well as estimations of the three candidates for an international stratotype, as summed up by Cowie from the last year's discussions.

On the whole, it should be said with certainty that the work under review, written by English colleagues, is very helpful for all professionals engaged in the problems of the Precambrian-Cambrian boundary. It is quite comprehensive an introduction to the course of the problem, even for a reader who is unacquainted with the problem. Despite the fact that $I$ do not share a number of the authors' statements, the publishing of this book was an important and very useful event for me, as I have been connected with the study of this boundary for over 30 years. $\square$

A.Yu. Rozanov

Moscow, USSR

\section{Tectonic Evolution of the Tethyan Region}

\section{A.M.C. Sengör (ed.)}

NATO ASI Series C: Mathematical and Physical Sciences, v. 259, Kluwer Academic Publishers, Dordrecht, 1989, 698 p., US $\$ 169.00$

This volume is a production of the North Atlantic Treaty Organization's (NATO) Advanced Study Institute on the Tectonic Evolution of the Tethyan Region. It contains the proceedings of the NATO meeting that was held at the faculty of mines, Istanbul Technical University, Istanbul, Turkey, from 23 September to 2 October 1986. The volume is dedicated to emeritus Professor Ishan Ketin, one of the founders of modern geology in Turkey. This is an assemblage of 27 papers that were presented at the Istanbul meeting, all on some aspect of Tethyan geology. The papers are ordered geographically from the Alps to the Indonesian region, and they cover a wide variety of topics.

The book starts with an interesting introduction by the editor, Dr. Sengör, on the Tethyan orogenic system and the history of research in the area. The main text begins with two papers on the western Alps, the first by J. Debelmas, who gives a useful summary of the tectonic evolution of this area, one of the most significant problems in the present-day interpretation of the belt. The second paper by R.W.H. Butler applies a model of linked thrust analysis to the Eocene to Pliocene tectonic evolution of the western Alps. He presents a useful series of balanced sections through the area in an attempt to unravel the complexity of the region. South-central Europe and the eastern Mediterranean are covered by a series of seven papers. M. Kázmér and S. Kováks treat the paleogeographic development of the
Carpathian-Pannonian region from the Triassic to the Cretaceous. Kováks describes the late Palaeozoic and Mesozoic tectonosedimentary evolution of northern Hungary. A.I. Okay deals with the complex geology of the Pontides of northwestern Turkey. D. Altiner compares the Middle to Late and post-Triassic rifting phases in southeastern Turkey and rejects the presence of a Triassic and Liassic ocean floor in southeastern Anatolia, Turkey, mainly on the basis of stratigraphic data from an area southwest of Lake Van. N. Görör summarizes new sedimentological data from the Rhodope-Pontide crustal fragment in northern Turkey and uses these data to postulate a Late Cretaceous backarc origin for the Black Sea. C. Kissel and others present paleomagnetic data, mainly from the eastern Aegean area, that suggest the late development of the present curvature of the Ionian-Lycian arc from an original rectilinear shape. Y. Yilmaz treats post-Oligocene volcanism in western Anatolia and its relationship with local tectonic evolution.

The Caucasian area is presented in only two papers. A.A. Belov gives a critical treatment of the tectonic evolution of Paleotethys in the Caucasus, and M.L. Bazhenov and V.S. Burtman present paleomagnetic data on Upper Cretaceous rocks from the greater and lesser Caucasus.

The most notable contribution on central Asia, and literally the central paper of the volume, is an extensive review by P. LeFort on the current understanding of the Himalayan orogenic segment. The paper contains a host of useful data and a 21-page reference list on the Himalayas. A useful addition is a paper by R.W.H. Butler and M.P Coward, who present balanced sections through the northwestern Himalayas and use these to estimate shortening across the Himalayan belt. West-central Asia is represented meagerly by, first, a discussion by J. Stöcklin on the geology of the Afghanistan-Pamirs region in the light of the expanding-Earth theory and, second, a contribution by A. Baud and G.M. Stämpfli on the geology of a small area in the Koppeh Dāgh in northeastern Iran. G.R. McCormick gives a preliminary report on the geology of Baluchistan (Pakistan).

A group of four papers reports on the Tibetan Plateau. Chang Chen and others summarize the available geological and geophysical data on the plateau. J. Girardeau and others compare neo-Cimmerian ophiolite belts in Afghanistan and Tibet, whereas $\mathrm{A}$. Baud presents an abstract that contains some data on the western part of the Tibetan Plateau. K. Burke and L. Lucas report on geological evidence from the Lunpola basin in the middle of the plateau that shows very young thrusting. 
Southern China is covered by two papers. K.J. Hsï and others describe the Mesozoic tectonic activity in southern China, and Zhang Qinwen and others summarize the tectonic evolution of the Yangtze terrane in this area. Southeast Asia is covered by four papers. A.H.G. Mitchell treats the Mesozoic and Cenozoic tectonic models for the evolution of western Burma. C.S. Hutchinson reviews orogenic systems in Southeast Asia, and $E$. Buffetaut presents a contribution on vertebrate paleontology to the geodynamic history of Southeast Asia. The last paper of the book is an extensive treatment by Warren Hamilton of plate tectonics in the Indonesian region.

In general, the book is a rather hybrid collection of papers in which the Himalayas and Southeast Asia are treated in some detail, but the rest of the Tethyan belt is covered very incompletely. Nevertheless, the book contains a lot of information, especially on remote areas, which may be of use to scientists occupied with large-scale tectonic modeling of parts of the Tethyan orogenic belt. The review papers are worth reading, even for the nonspecialist. A major drawback of this book is the absence of an extensive review of the tectonic evolution of the Tethyan region. The editor gives an interesting introduction to the subject, but more detailed coverage would have been welcome. Notably, central Asia is covered only fragmentarily, and the papers on local geology in this area are difficult to follow for scientists who are unfamiliar with the region. In its present state, the text is most useful to scientists who are actively involved in research in parts of the Tethyan belt; for those scientists, I can recommend this volume.

Cees W. Passchier

Utrecht, The Netherlands

\section{The Geology of Egypt}

\section{Rushdi Said}

A.A. Balkema Publishers, Rotterdam, 1989, 734 p., US $\$ 85.00$

Rushdi Said, the former Head of the Egyptian Geological Survey, presents a compilation and synthesis of the geological literature of Egypt that has been published since 1962. He uses the same title as his earlier book "The Geology of Egypt," which came out in 1962. The book presents articles written mostly by local geologists who have contributed enormously to our understanding of Egyptian geology (for example, M. Meneissy, O. Cherif, R. Said, and M. Ayouty).
Regional-scale data (gravity, seismic, Landsat, geomorphologic, and Phanerozoic radiometric data) are analyzed in part 1 , and the basement complex is described in part 2 . The regional geology of selected areas (for example, northern and southern parts of the Western Desert, Nile delta, and Red Sea coastal plains) is discussed in part 3. The Paleozoic, Mesozoic, Cenozoic, and Quaternary time periods are discussed in part 4. Resources (ground water, oil, and minerals) and selected paleontological studies are considered in parts 5 and 6 , respectively. Reference are given in part 7.

Readers interested in sedimentation and volcanism during the Phanerozoic will find the book instructive; others interested in the Proterozoic tectonic framework of Egypt will be less content. Only 3 articles out of 32 deal with the Proterozoic, and statements and ideas are expressed that are inconsistent with published geochronologic and isotopic data. Despite the fact that published uranium-lead (zircon) and rubidiumstrontium data preclude the presence of a
pre-Pan African infrastructure in the Eastern Desert, references to this older crust are advocated repeatedly in chapters 10 and 12 . Titles for sections referred to as "parts" in the book are not appropriate. For example, mineral deposits, petroleum, and aquifers, discussed in chapters 26,27 , and 28 , respectively, are grouped in part 5, which is titled "Economic Mineral Deposits." Similar arguments apply to parts 1 and 4. Some of the articles tend to reflect strongly the preferred interpretations of individual authors to such an extent that important contributions by other workers are ignored.

The book is well written and has easily readable type, and the illustrations are clear. Despite the few inadequacies discussed above. "The Geology of Egypt" serves as a good reference, as it is wide in scope and brings together a wealth of geologic information that is difficult to obtain otherwise. It also could serve as a textbook for senior undergraduate or graduate courses in Egyptian universities. Because the book provides the only updated textbook on the geology of

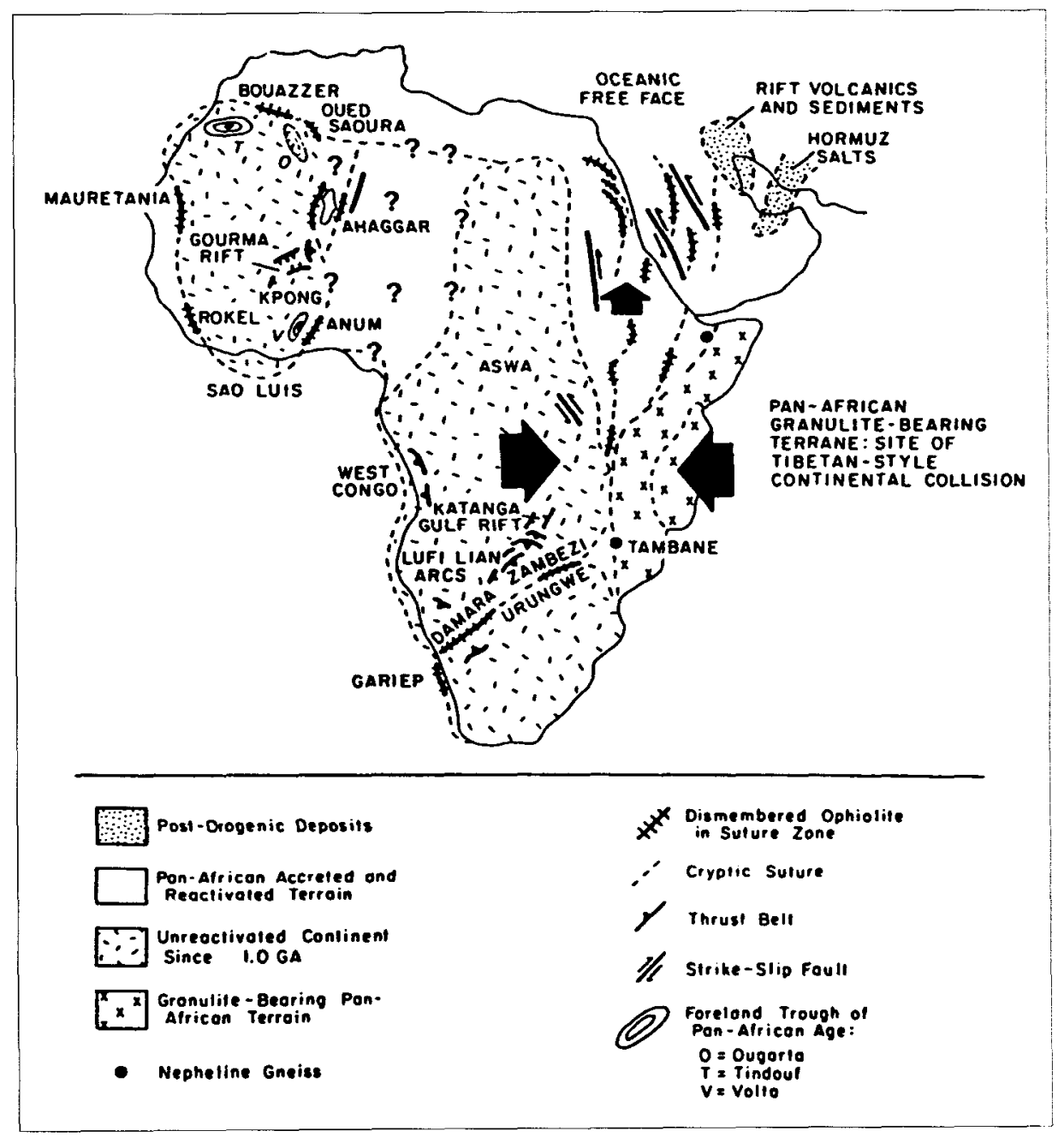


Egypt, I find it to be a significant and welcomed achievement. $\square$

Mohamed I. Sultan

St. Louis, Missouri, USA

\section{Mass Extinctions-Processes and Evidence}

\section{Stephen K. Donovan (ed.)}

Pinter Publishers, London, 1989, 259

p., hardbound, $£ 32.00$

Of the dozens, if not hundreds, of geological talks, lectures, and seminars that most of us encounter in our careers as earth scientists, very occasionally one comes along that falls in the "inspired" or "mindexpanding" category. For me, one of these occurred while I was a graduate student in Canberra, Australia, in the early 1980s. In a public lecture, Walter Alvarez (USA) presented the evidence for the impact of a large extraterrestrial object and its probable causal relationship with mass extinctions at the end of the Cretaceous. The implications for paleontology left my imagination cartwheeling. Because of D.M. Raup and J.J. Sepkoski, Jr.'s, (USA) announcement soon after of an apparent 26-million-year periodicity of mass extinctions, at least during the later Phanerozoic, and the plausible hypothesis that these too might be driven by impacts, it seemed that paleontology was on the verge of a unifying theory of mass extinctions and biotic diversity through time.

Puzzling to me at that time was the general lack of enthusiasm for the idea on the part of my more established paleontological colleagues. I suspected that their objections, rased mostly on the apparent protracted nature of major extinctions, were mere quibblings that were bound to disappear as more detailed sampling of biotas was obtained across the key boundaries. My attempts to keep up with the debate have since faltered in the ensuing blizzard of extinction-related papers, many of them dealing with complex aspects of geochemistry, statistical analyses of periodicity, diversity gradients across key boundaries, and even astronomy. Not being involved personally in extinction studies, I began to wonder just where the debate stood.

I was delighted, therefore, to encounter "Mass Extinctions - Processes and Evidence." Recognizing a lack of adequate summary books in the literature, editor
Stephen Donovan summoned the expertise of a number of authors in order to provide a detailed account of the major extinctions recognized in the fossil record. The result is a well-written and well-edited volume that provides an excellent overview for both the professional and the advanced student.

The necessary background for understanding extinction studies is given in the first three chapters. These begin with a historical sketch of paleontological views on mass extinctions (A. Hoffman), which is followed by an outline of paleontological criteria for recognizing mass extinctions (S.K. Donovan) and then by a guide to geochemical studies at mass-extinction horizons (C.J. Orth). The last contribution is especially helpful. After providing a concise explanation of the principal geochemical techniques used at extinction boundaries, Orth reviews geochemical data and their interpretation for 16 bioevent horizons spanning the Precambrian-Cambrian boundary to the late Pliocene. He concludes (p. 67) that, although several probable impact horizons occur in Tertiary sediments, ". . . thus far there is no convincing evidence of an impact-extinction relationship in those [bioevent horizons] older than the terminal Cretaceous event."

In the ensuing chapters, principal extinction events in the history of life are reviewed one after another. These include five chapters on the major "crises," namely, the end of the Ordovician (P.J. Brenchley), the Frasnian-Fammenian (G.R. McGhee, Jr.), the end of the Permian (W.D. Maxwell), the Late Triassic (A.L.A. Johnson and M.J. Simms), and the end of the Cretaceous (G.R. Upchurch, Jr.), as well as four other chapters on lesser, though instructive, extinctions, namely the late Precambrian (M.D. Brasier), the Late Cambrian (S.R. Westrop), the Eocene-Oligocene (D.R. Prothero), and the late Pleistocene (A.D. Barnosky). Although I am sure that the editor Donovan originally visualized a concise but thorough review of biotic change for each of these extinctions, the result is varied, as some authors focus on only a select group of organisms, and other authors are more comprehensive taxonomically in their discussion. However, this proves to be strength, rather than a weakness, in that the reader is left with a good sense of the nature and limitations of the paleontologic data across a range of taxonomic scales from whole biotas to restricted groups. In these chapters, the authors discuss, in varying degrees of detail, the paleontologic and geo- logic data associated with the extinction event (or events), and then they evaluate hypothesized mechanisms. The combined result is sobering for anyone who thinks that we are close to a unified theory of mass extinctions based on periodic impacts. Nearly all the authors conclude that mass extinctions occur either gradually or in a steplike pattern over a geologically significant time interval. For example, McGhee (p. 145) states, "The Frasnian-Fammenian event was not instantaneous, in that multiple periods of high extinction rates existed in the late Frasnian. spanning an interval of 2-4 million years." Similarly, Prothero (p. 226) concludes that the Eocene-Oligocene extinctions are characterized by "at least five steps of extinction .

. spaced out over 10 million years." Nearly all evoke terrestrial factors (tectonic, climatic, biotic), rather than a bolide impact or impacts, as the most probable mechanism for extinction. Upchurch is the exception. In his review of paleobotanical data across the Cretaceous-Tertiary boundary, he rejects gradual climatic change as a mechanism for extinction. He states (p. 203), "Palynofloras and leaf floras from non-polar regions of North America clearly indicate a [bolideinduced] mass-kill event that was followed by a succession-like pattern of recovery." Other authors (for example, Brenchley, McGhee, Prothero) do not wholly discount an impact or series of impacts as, at least, contributory agents of extinction, but they cite the lack of geochemical and other physical data as a serious objection.

This book is a vivid reminder that, in the midst of multidisciplinary studies on mass extinctions, the paleontologic data are the primary evidence that requires explanation. The "quibblings" of paleontologists have not disappeared. Instead, they have been largely verified and may prove ultimately lethal to a generalized theory of extinctions based on extraterrestrial impacts. One gets the impression that, although little concensus exists about the causal agents of extinctions, at least the paleontologic patterns across the extinction intervals are being clarified. With this, the onus is shifting largely to geologists, geochemists, and astronomers to show how extraterrestrial mechanisms might account for protracted extinction intervals, as well as whether an extraterrestrial mechanism can, in some way, trigger longer term terrestrial mechanismsif, in fact, a general causative extraterrestrial mechanism exists at all. $\square$

Paul A. Johnston

Drumheller, Alberta, Canada 